\title{
Обзоры и лекции
}

\author{
(C) БЕКЕТОВА Т.В., НАСОНОВ Е.В., 2020
}

\author{
Бекетова Т.В., Насонов Е.В.
}

\section{ВАСКУЛОПАТИЯ У ПАЦИЕНТОВ С COVID-19 ТЯЖЕЛОГО ТЕЧЕНИЯ}

\author{
ФГБНУ «Научно-исследовательский институт ревматологии им. В.А. Насоновой», 115522, Москва, Россия
}

Представлен обзор литературы, посвященной одному из проявлений коронавирусной инфекции (corona virus disease-19, COVID-19) тяжелого течения, к которым относят патологические изменения в сосудах микрочиркуляиии, что можно рассматривать в рамках системного васкулита (CB) или васкулопатии. Поскольку в настоящее время универсальной стратегии лечения COVID-19 не разработано, расшифровка патоморфологии и патогенеза заболевания может стать основанием для поиска эффективных методов лечения.

Наряду с тяжелым прогрессирующим поражением легких у паџиентов с COVID-19 может присутствовать полиорганная симптоматика, напоминающая CB. Получены доказательства при COVID-19 тяжелого течения участия системы комплемента с отложениями в сосудах микроциркулячии легких и других органов C5b-9 и C4d, cвидетельствующего об активации альтернативного и лектинового путей, что сопровождается повреждением эндотелиальных клеток, каскадом воспалительных реакиий и тромбофилией. Это дает основания рассматривать ряд стратегических направлений в лечении COVID-19.

Поскольку при различных тромботических микроангиопатиях эффективна стратегия, направленная на систему комплемента, появляются основания обсуждать перспективы применения для лечения COVID-19 тяжелого течения ингибиторов C5-компонента комплемента экулизумаба, равулизумаба и селективного ингибитора рецептора C5aRl авакопана, в клинических исследованиях доказавшего свою эффективность при АНЦА-СВ как альтернатива глюкокортикоидам. Тяжелое течение COVID-19 осложняется иммунопатологической реакиией с высвобождением широкого спектра провоспалительных ичитокинов и хемокинов, что ассоциируется с неблагоприятным прогнозом. Так как для лечения синдрома высвобождения цитокинов при различных состояниях эффективны ингибиторы интерлейкина-6, у пациентов с тяжелым/катастрофическим COVID-19 применяют тоцилизумаб и сарилумаб. Возможная эффективность при COVID-19 ингибитора JАК барицитиниба обусловлена как его противовоспалительной активностью, так и способностью подавлять раннюю стадию репликации коронавируса.

COVID-19 тяжелого течения может сопровождаться распространенной сосудистой патологией прежде всего микроциркуляторного русла и тромбофилией, что следует учитывать при планировании новых стратегий лечения. Кл юч е в ы е сл о в а : COVID-19; лечение; васкулит; васкулопатия.

Для цитирования: Бекетова Т.В., Насонов Е.В. Васкулопатия у пациентов с COVID-19 тяжелого течения. Клиническая медицина. 2020;98(5):325-333. DOI: http://dx.doi.org/10.30629/0023-2149-2020-98-5-325-333

Для корреспонденции: Бекетова Татьяна Валентиновна — д-р мед. наук, врач-ревматолог, ведущий научный сотрудник лаборатории микроциркуляции и воспаления; e-mail: tvbek@rambler.ru

\section{Beketova T.V., Nasonov E.V.}

\section{VASCULOPATHY IN PATIENTS WITH SEVERE COVID-19 INFECTION}

V.A. Nasonova Scientific and Research Institute of Rheumatology, 115522, Moscow, Russia

Presented review elucidates one of the manifestations of severe corona virus disease-19, (COVID-19) associated with pathological changes in the microvasculature which can be considered in the context of systemic vasculitis (SV) or vasculopathy. Since there is currently no universal treatment strategy for COVID-19, better understanding of pathomorphology and pathogenesis will provide the foundation for potentially effective therapeutic interventions.

Along with severe progressive lung damage, patients with COVID-19 often have multiple organ symptoms resembling SV. Evidence of complement-mediated injury in severe COVID-19 comes with C5b-9 and C4d deposition in the microvasculature of lungs and other organs, which is consistent with generalized activation of both alternative and lectin-based pathways, accompanied by damage to endothelial cells, the inflammatory cascade, and hypercoagulation. Thus, there are arguments in favor of a number of therapeutic strategies for COVID-19.

Since inhibitors of the C5 component of the complement (eculizumab, ravulizumab) is effective in various thrombotic microangiopathies, and the selective C5aRI receptor inhibitor avacopan has proven effective for ANCA-SV, strategy targeted at the complement system look as promising in severe COVID-19. The COVID-19 infection has been observed to induce proinflammatory cytokine and chemokines generation, which is associated with an unfavorable prognosis. Since interleukin-6 inhibitors are effective for the treatment of cytokine release syndrome in various conditions, tocilizumab and sarilumab are used in patients with severe/ catastrophic COVID-19. The relevance and potential effectiveness of JAK inhibitor baricitinib in COVID-19 originates from its anti-inflammatory activity and ability to suppress the early stage of coronavirus replication. Severe COVID-19 infection can be accompanied by generalized vascular pathology, mainly the microvascular, and thrombophilia, which should be considered when planning new treatment strategies.

K e y w ord s : COVID-19; treatment; vasculitis; vasculopathy.

For citation: Beketova T.V., Nasonov E.V. Vasculopathy in patients with severe COVID-19 infection. Klinicheskaya meditsina. 2020;98(5):325-333. DOI: http://dx.doi.org/10.30629/0023-2149-2020-98-5-325-333

For correspondence: Tatiana V. Beketova - MD, $\mathrm{PhD}$, DSc, rheumatologist, leading researcher at the laboratory of microcirculation and inflammation; e-mail: tvbek@rambler.ru 
Conflict of interests. The authors declare no conflict of interests.

Acknowlegments. The study had no sponsorship.

Information about authors

Beketova T.V., https://orcid.org/0000-0003-2641-9785

Nasonov E.V., https://orcid.org/0000-0002-7177-2409

Received 05.04.20

Стремительное развитие пандемии коронавирусной инфекции (corona virus disease-19, COVID-19) требует неотложного решения принципиально новых клинических и фундаментальных проблем иммунопатологии заболеваний человека, которые во многом еще только предстоит сформулировать [1]. В настоящее время универсальной стратегии лечения COVID-19 не найдено, что формирует высокую актуальность изучения патологических механизмов COVID-19, особенно при тяжелом и катастрофическом течении, расшифровка которых может стать основой для разработки эффективных методов лечения. Несмотря на большое количество публикаций, за последние 4 мес. насчитывающее более 6700 научных статей, посвященных COVID-19, в настоящее время представления о проблеме находятся лишь на этапе становления. В данном обзоре обсуждается литература, посвященная одному из проявлений тяжелого течения COVID-19, к которым относят распространенную сосудистую патологию, что можно рассматривать в рамках системного васкулита (CB) или васкулопатии.

Некоторые особенности COVID-19 тяжелого течения свидетельствуют о присутствии патологических иммуновоспалительных реакций во время противовирусного ответа, способствующих генерализованной дисфункции микроциркуляторного русла, гиперкоагуляции, воспалительным реакциям, что может приводить к полиорганному поражению.

Через 1-2 нед. после манифестации COVID-19 состояние пациентов в ряде случаев резко ухудшается, тяжелому прогрессирующему поражению легких нередко сопутствуют симптомы поражения различных органов и систем, напоминающие $\mathrm{CB}$, вплоть до гангрены конечностей, что сопровождается гиперкоагуляцией с высоким уровнем D-димера и крайне высокой лабораторной воспалительной активностью с повышением уровня С-реактивного белка (СРБ), ферритина и провоспалительных цитокинов [2-4]. Полагают, что быстрое высвобождение широкого спектра провоспалительных цитокинов и хемокинов (так называемый цитокиновый шторм) приводит к развитию острого респираторного дистресс-синдрома (ОРДС) у пациентов, находящихся в критическом состоянии $[1,5,6]$. На следующей стадии COVID-19, примерно 3-5-я нед. заболевания, на фоне обширного повреждения легких прогрессирует тромботическая микроангиопатия, продолжается проникновение компонентов плазмы во внесосудистое пространство и запускаются процессы фиброзной трансформации легочной ткани, что в исходе может формировать поствоспалительный интерстициальный фиброз легких различной степени и протяженности $[6,7]$.

Для иммунных нарушений при COVID-19 характерна лимфопения со снижением в периферической крови содержания Т-клеток и естественных киллеров (NK клеток), в тяжелых случаях - снижение Т-клеток памяти и регуляторных Т-клеток, увеличение числа высоко патогенных CCR4+CCR6+ Th17-клеток и высокая цитотоксичность CD8+ T-клеток, повышение числа Th1-клеток, синтезирующих гранулоцитарно-макрофагальный колониестимулирующий фактор [3, 5, 8-12]. В легочной ткани преобладает инфильтрация моноцитами и макрофагами, присутствуют нейтрофилы и в небольшом количестве лимфоциты, наблюдается атрофия селезенки и лимфатических узлов, снижение количества лимфоцитов в лимфоидных органах $[3,13]$.

При крайне тяжелом или катастрофическом течении COVID-19 спектр цитокинов и хемокинов напоминает вторичный гемофагоцитарный синдром и характеризуется высокой гиперпродукцией интерлейкина (ИЛ) -6, ИЛ-1 $\beta$, ИЛ-2, ИЛ-7, ИЛ-8, фактора некроза опухоли $\alpha$, хемокинов CXCL10 и моноцитарного хемотаксического протеина-1 [3, 9, 14, 15]. Показано, что уровень ИЛ-6 коррелирует с вирусной нагрузкой и плохим прогнозом COVID-19 [16]. Высокая сывороточная концентрация ИЛ-6, ферритина и D-димера ассоциируется с тяжелым течением COVID-19 и риском летального исхода, при этом повышение ИЛ-6> 24,3 пг/мл рассматривают в качестве фактора неблагоприятного прогноза COVID-19 с чувствительностью и специфичностью 73,3 и $89,3 \%$ соответственно [16-18].

COVID-19 тяжелого течения протекает со значительными нарушениями системы гемостаза и может сопровождаться тромбозами легочных артерий, в ряде случаев с кровохарканьем, осложняться синдромом диссеминированного внутрисосудистого свертывания (ДВС), развитие которого, по данным N. Tang и соавт., наблюдается в $2 / 3$ случаев с летальным исходом COVID-19 и только у 6\% выживших пациентов [19-21]. В некоторых случаях выявляют высокие уровни антифосфолипидных антител, антител к кардиолипину и $\beta 2$-гликопротеину, что ассоциируется с тяжелыми тромботическими осложнениями $[3,4]$. Следует отметить, что антифосфолипидные антитела могут повышаться транзиторно при различных острых инфекциях.

По данным D. Caruso и соавт. [22], у 52 (89\%) из 58 пациентов с COVID-19 и поражением легких при MCКТ грудной клетки легких обнаружено расширение 
Обзоры и лекции

субсегментарных легочных сосудов $>3$ мм. I. LeonardLorant и соавт. [23] при КТ ангиографии у 32 (30\%) из 106 обследованных пациентов с COVID-19 выявили признаки острой тромбоэмболии легочных артерий (в том числе у 14 из 32 с поражением сегментарных или субсегментарных артерий), что во всех случаях сочеталось с повышением D-димера $>2660$ мкг/л. По данным F. Grillet и соавт. [24], у пациентов с COVID-19 тяжелого течения частота острой тромбоэмболии легочных артерий, диагностированной в среднем через 12 дней от начала заболевания, при КТ ангиографии составила 23\% (у 23 из 100 пациентов). Голландские исследователи среди 184 больных COVID-19, находящихся в отделении интенсивной терапии (ОИТ) и получавших лечение, направленное на профилактику тромбоза, у $31 \%$ выявили тромбоэмболические осложнения, при этом преобладали венозные тромбозы (27\%), случаи ДВС-синдрома не отмечены [25]. В одном из итальянских центров 20 пациентов с COVID-19 получали лечение в связи с развитием острой ишемии конечности, при этом отмечено существенное повышение числа случаев острой ишемии конечностей в первом квартале 2020 г. в сравнении соответствующим периодом 2019 г. (соответственно 16,3 и $1,8 \%$ ) [26].

Механизм поражения сосудов при COVID-19 тяжелого течения, возможно, обусловлен прямым повреждением эндотелиальных клеток различных органов коронавирусом и тромбофилией, что формирует патологический процесс, который можно описывать как СВ или васкулопатию [27]. Нередко наряду с пневмонией развивается системная патология с поражением почек, желудочно-кишечного тракта, кожи, центральной нервной системы, сердца $[2,5,9,13,28-32]$. Таким образом, COVID-19 может иметь черты вторичных системных васкулитов, таких как криоглобулинемический васкулит, ассоциированный преимущественно с вирусом гепатита $\mathrm{C}$, и узелковый полиартериит, наиболее часто обусловленный вирусом гепатита В.

Частота внелегочных проявлений варьируется по данным различных авторов. Так, в китайском исследовании, проанализировавшем 1099 случаев COVID-19, среди 173 (15,7\%) пациентов с тяжелым течением частота миалгий/артралгий составила $17,3 \%$, диареи $-5,8 \%$, острого поражения почек - $2,9 \%$, конъюнктивита $-2,3 \%$, кожных высыпаний - 1,2\% [30]. В другой китайской когорте, включившей 140 госпитализированных пациентов с COVID-19, среди 58 (41\%) случаев тяжелого течения заболевания желудочно-кишечные симптомы отмечались у $42,1 \%$, в том числе диарея - у 15,8\% [9]. S. Recalcati наблюдал выраженные кожные изменения, не связанные с приемом лекарственных препаратов, у 20\% (18 из 88) госпитализированных пациентов с COVID-19, как правило, в виде эритематозных высыпаний (16\%) прежде всего на туловище, реже - генерализованной крапивницы (3\%), пятнисто-везикулезных высыпаний (1\%) [31]. Испанские исследователи описали 375 пациентов с COVID-19 и поражением кожи, наиболее часто представленным макулопапулезными (47\%) и уртикарными (19\%) высыпаниями, акральным дерматитом, напоминающим обморожение, с эритематозными, везикулярными и пустулезными элементами (19\%), реже - другими везикулярными высыпаниями (9\%), ливедо или участками некроза (6\%), при этом в $15 \%$ случаев поражение кожи было манифестным проявлением COVID-19 [32]. По данным L. Мао и соавт. [33], у 45,5\% пациентов с тяжелым COVID-19 присутствовала неврологическая симптоматика, в том числе у $30,7 \%$ - поражение центральной нервной системы, включая острое нарушение мозгового кровообращения $(5,7 \%)$ и расстройства сознания $(14,8 \%)$, у $8 \%$ - периферическая нейропатия. Отмечается аносмия и дисгевзия, повреждение скелетных мышц с повышением уровня креатининкиназы $(19,3 \%)$ [33, 34]. COVID-19 может осложняться полиорганным поражением со значительным повышением уровня печеночных ферментов и почечной недостаточностью [30, 32, 34], частота которой достигает 15\% [35].

Несмотря на большое число летальных исходов в мире, исследования, посвященные патоморфологии COVID-19, в настоящее время крайне ограничены. Предварительные данные изучения аутопсий пациентов с COVID-19 в Италии выявили признаки тромбоза и тромбоваскулита в мелких сосудах легких, головного мозга, кожи, других органов, что дало основание авторам обсуждать возможность повреждения сосудов на ранних этапах интерстициальной пневмонии у пациентов с COVID-19 [2]. Это может объяснять преимущественное поражение нижних отделов легких, которым свойственны наиболее высокие значения легочного кровотока на единицу объема ткани и преобладание перфузии $[7,36]$.

У пациентов c COVID-19 тяжелого течения при морфологическом исследовании легочной ткани в сосудах альвеолярных перегородок обнаруживают застойные явления с отеком и умеренной периваскулярной инфильтрацией моноцитами и лимфоцитами, отмечается гиперплазия, утолщение стенок мелких сосудов со стенозом или окклюзией просвета, очаги кровоизлияния [3]. Могут присутствовать микрососудистые гиалиновые тромбы $[9,11,37]$. При исследовании пораженной кожи описаны микрососудистые тромбы, периваскулярная инфильтрация нейтрофилами, лимфоцитами, в небольшом количестве - эозинофилами [29]. В ткани почек больных COVID-19 выявлено присутствие вирионов в цитоплазме клеток канальцевого эпителия и подоцитах, выраженное острое повреждение проксимальных почечных канальцев, местами с некрозом, окклюзия мелких сосудов, преимущественно эритроцитами, при этом признаки интерстициального воспаления отсутствовали [35].

С. Magro и соавт. [13] представили результаты морфологического исследования кожи и легочной ткани у 5 пациентов с тяжелым течением COVID-19, во всех случаях с поражением легких и дыхательной недоста- 
точностью, у 3 пациентов с изменениями кожи в виде пурпуры или ливедо, сопровождавшимися существенным повышением D-димера. В легких описано поражение септальных капилляров с отложением фибрина, нейтрофильная инфильтрация межальвеолярных перегородок и значительные отложения в сосудах микроциркуляции компонентов терминального комплекса комплемента C5b-9 (мембраноатакующий комплекс), $\mathrm{C} 4 \mathrm{~d}$ и маннозо-связывающий лектин (MBL), ассоциированной сериновой протеазы (MASP) 2, что свидетельствует об активации альтернативного и лектинового путей системы комплемента. В коже с пурпурой или ливедо отмечались явления тромботической васкулопатии, а в образцах как интактной, так и измененной кожи отложения C5b-9 и C4d. У 2 из 5 пациентов в межальвеолярных перегородках легких и мелких сосудах кожи выявлено совместное отложение гликопротеинов коронавируса и С4d, C5b-9.

Следует упомянуть, что нейтрофилы, премированные в условиях инфекции и/или продукции провоспалительных цитокинов, высвобождают пропердин, активирующий альтернативный путь комплемента с расщеплением C5 на С5a и C5b. Последний приводит к формированию мембраноатакующего комплекса C5b-9, в то время как С5а связывается с соответствующими рецепторами на поверхности нейтрофилов и других клеток. Взаимодействие С5a с рецептором C5aR1, активирующим нейтрофилы, формирует амплификационную петлю за счет высвобождения нейтрофилами пропердина, что приводит к дальнейшему усилению альтернативного каскада с увеличением продукции C5a [38]. Неконтролируемое формирование терминальных компонентов активации комплемента С5a и C5b-9 способствует повреждению эндотелиальных клеток, тромбоцитов, эритроцитов.

Таким образом, COVID-19 может сопровождаться системной сосудистой патологией с активацией преимущественно альтернативного и лектинового путей системы комплемента, каскадом воспалительных реакций и тромбофилией, что дает основания рассматривать ряд стратегических направлений в лечении COVID-19.

Активация альтернативного пути комплемента с отложением C5b-9, повреждением эндотелиальных клеток и развитием микрососудистого тромбоза является ключевой особенностью таких тромботических микроангиопатий (ТМА), как катастрофический антифосфолипидный синдром (АФС), атипичный гемолитический уремический синдром (АГУС), злокачественный атрофический папулез, трансплантат-ассоциированная тромботическая микроангиопатия, при которых получены данные об эффективности терапевтической стратегии, направленной на систему комплемента [38]. Так, применение гуманизированного моноклональ-

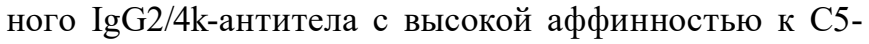
компоненту комплемента экулизумаба при катастрофическом АФС позволяло контролировать острые про- явления АФС и предотвращало повторные тромбозы [39]. При АГУС, в основе которого лежит ТМА с неконтролируемой активацией комплемента, в нескольких клинических исследованиях была продемонстрирована эффективность экулизумаба, способствовавшего предотвращению явлений ТМА с нормализацией гематологических показателей и улучшением функции почек [40-43]. Для лечения АГУС и пароксизмальной ночной гемоглобинурии разработано еще одно моноклональное антитело - ингибитор комплемента С5 длительного действия равулизумаб [44]. Лечение антителами к С5-компоненту комплемента требует профилактики бактериальных инфекций, рекомендуют вакцинировать пациентов против менингококка за 2 нед. до применения экулизумаба или равулизумаба, при этом отмечают, что высокий риск менингококковой инфекции сохраняется, несмотря на вакцинацию [45]. В то же время, по данным японских исследователей, среди 27 детей с АГУС, получавших лечение экулизумабом (54\% - на фоне менингококковой вакцинации, 15\% - с профилактическим приемом антибиотиков), не было зарегистрировано летальных исходов, связанных с применением препарата или менингококковой инфекцией [46].

Получены предварительные положительные результаты исследования (NCT02464891) у пациентов с АГУС, находящихся на программном гемодиализе, нового перорального низкомолекулярного селективного ингибитора рецептора C5aR1 авакопана (CCX168). Авакопан доказал свою эффективность при АНЦА-ассоциированных СВ как альтернатива глюкокортикоидам (ГК) в 2 предварительных клинических исследованиях II фазы и по результатам рандомизированного плацебо-контролируемого (РПКИ) III фазы ADVOCATE, в котором использование авакопана вместо ГК в схеме индукционной терапии, включавшей циклофосфан или ритуксимаб, позволяло достигать полной и устойчивой ремиссии АНЦА-СВ при удовлетворительном профиле безопасности [47-49]. Поскольку авакопан селективно блокирует C5aR1 и не связывается с ингибирующим нейтрофилы рецептором C5aR2, то в отличие от блокаторов расщепления С5 (экулизумаб, равулизумаб), не оказывает влияния на образование С5b и мембраноатакующего комплекса C5b-9, тем самым не повышает риск развития тяжелых бактериальных инфекций, в том числе менингококковой.

Таким образом, имеются основания обсуждать перспективы применения для лечения COVID-19 тяжелого течения селективного ингибитора рецептора C5aR1 (авакопан) и ингибиторов C5-компонента комплемента (экулизумаб, равулизумаб). F. Diurno и соавт. [50] опубликовали подробный отчет применения экулизумаба у 4 больных COVID-19 с тяжелой пневмонией или ОРДС. В результате лечения все пациенты успешно восстановили функции, уровень СРБ снизился в среднем с 146 до 35 мг/л, при этом средняя продолжительность заболевания составила 12,8 дня. Вместе с тем для применения ингибиторов С5-компонента комплемента при 
Обзоры и лекции

COVID-19 имеются ограничения, поскольку механизм их действия предполагает повышение развития бактериальных инфекций, прежде всего менингококковой. Внедрение в клиническую практику дополнительно сдерживает высокая стоимость экулизумаба, который относят к числу наиболее дорогостоящих генно-инженерных биологических препаратов (ГИБП). Разработка авакопана в настоящее время находится на дорегистрационном этапе.

Активация системы комплемента альтернативного и лектинового путей при COVID-19 может быть связана с провоспалительными механизмами действия ангиотензина II [51]. S-гликопротеин коронавируса имеет высокую аффинность к мембранному протеину ангиотензин-превращающему ферменту (АПФ) 2, присутствующему в клетках альвеолярного эпителия легких, тканях сердца, почек, мозга, кровеносных сосудов, и использует его как точку входа в клетку $[28,52,53]$. Следует упомянуть, что на АПФ2, в отличие от АПФ1, не оказывают действие препараты из класса ингибиторов АПФ. Биологическая функция АПФ2 включает превращение ангиотензина I в ангиотензин 1-9, ангиотензина II в ангиотензин 1-7, при этом происходит инактивация ангиотензина II, являющегося медиатором окислительного стресса и стимулирующего экспрессию молекул клеточной адгезии и продукцию провоспалительных цитокинов. Образующийся ангиотензин 1-7, напротив, способствует уменьшению оксидативного стресса, пролиферации и фиброза [54]. Предполагают, что коронавирус может подавлять АПФ2 и приводить к избыточному накоплению ангиотензина II и брадикинина, тем самым способствуя эндотелиальной дисфункции, воспалению, рекрутированию тромбоцитов $[27,55,56]$. Активация легочного эндотелия может приводить к быстрому, но непродолжительному высвобождению АПФ1, катализирующему расщепление ангиотензина I до ангиотензина II, что вызывает увеличение количества последнего, усиливая воспаление, нарушения гемостаза. Последующая фаза со снижением АПФ1 и ангиотензина II приводит к расширению сосудов, эндотелиальной дисфункции, низкая концентрация ангиотензина II активирует АПФ2, возможно, повышая восприимчивость тканей к коронавирусу. Все это провоцирует прогрессирование заболевания с развитием ОРДС и поражением различных органов [57, 58].

Интересно, что количество АПФ2 на клеточной мембране потенциально может уменьшать плейотропный препарат мелатонин, тем самым снижая способность коронавируса прикрепляться к клеткам различных органов, что было выявлено при интегративном биоинформатическом анализе ранжирования потенциальных мишеней коронавируса и противовирусных препаратов [59]. Это может косвенно свидетельствовать в пользу участия в качестве переносчиков коронавируса летучих мышей, ночных животных с возможной естественной защитой от вирусов, аффинных к АПФ2. В этой связи обсуждается потенциальная эффективность при- менения на ранней стадии COVID-19 мелатонина в сочетании с гидроксихлорохином, а также затемнение палат интенсивной терапии для усиления синтеза эндогенного мелатонина у пациентов с COVID-19 [56, 59].

Прогрессированию ОРДС способствует снижение фибринолитической активности, что преимущественно объясняют повышением ингибитора активатора плазминогена-1 в плазме и жидкости бронхоальвеолярного лаважа [60]. В экспериментальных и клинических исследованиях получены свидетельства улучшения выживаемости при остром повреждении легких и ОРДС в результате фибринолитической терапии $(p=0,0008)$, что стало основанием обсуждения перспектив применения активатора тканевого плазминогена у больных COVID-19 для снижения тяжести ОРДС и улучшения прогноза, получившего подтверждение в имитационной аналитической модели [60-62]. J. Wang и соавт. [63] опубликовали положительный опыт лечения 3 пациентов с COVID-19 и ОРДС активатором тканевого плазминогена (альтеплаза) и гепарином. Во всех случаях введение альтеплазы способствовало выраженному улучшению, которое сохранялось в течение всего периода введения препарата. После завершения лечения альтеплазой умер 1 из 3 пациентов, имевший полиорганную недостаточность и потребность в гемодиализе.

Тяжелое и катастрофическое течение COVID-19 с развитием ОРДС и полиорганной недостаточности связывают с синдромом высвобождения цитокинов (цитокиновый шторм), при этом ключевую роль отводят ИЛ-6 и ИЛ-1 [1, 5, 14, 64, 65]. Поскольку для лечения синдрома высвобождения цитокинов при различных состояниях эффективны ингибиторы ИЛ-6 и ИЛ-1, их применение рассматривают как перспективное направление лечения пациентов с тяжелым/катастрофическим COVID-19 [65-72]. Ингибицию плейотропного цитокина ИЛ-6 применяют при широком круге заболеваний, прежде всего в ревматологии [66]. Тоцилизумаб, моноклональное антитело IgG1 к рецептору ИЛ-6, зарегистрирован в мире и России к применению в детском возрасте при ювенильном идиопатическом артрите, у взрослых - при ревматоидном артрите и гигантоклеточном артериите, васкулите крупных сосудов, преимущественно развивающемся в пожилом возрасте и нередко у пациентов с мультиморбидной патологией. Эффективность ингибиторов ИЛ-6 продемонстрирована в клинических исследованиях и при других СВ (АНЦА-СВ артериит Такаясу, болезнь Бехчета), а также системной красной волчанке $[66,71]$. Поскольку при COVID-19 в исходе пневмонии может формироваться интерстициальный фиброз легких, большой интерес представляет потенциальный эффект тоцилизумаба при системной склеродермии в отношении сдерживания прогрессирования фиброза легких и кожи [73].

Эффективность тоцилизумаба при COVID-19 продемонстрирована в небольшом числе клинических исследований и в последнее время получает подтверждение в клинической практике. В Китае были опублико- 
ваны (без внешнего рецензирования) предварительные результаты применения тоцилизумаба у 21 пациента с тяжелым/катастрофическим течением COVID-19. После введения тоцилизумаба внутривенно (в/в) 400 мг однократно (у 3 пациентов дополнительно еще 1 раз через 12 ч) отмечено быстрое снижение лихорадки, нормализация уровня СРБ, а у 15 (75\%) из 20 пациентовснижение потребности в терапии кислородом, 19 пациентов были выписаны в среднем через 13,5 $\pm 3,1$ дня госпитализации после лечения тоцилизумабом [74]. Эти результаты стали основанием для включения тоцилизумаба в протоколы лечения COVID-19 в различных странах, в том числе в России, при тяжелом поражении легких с высоким содержанием в сыворотке крови ИЛ-6.

В настоящее время эффективность и безопасность применения ингибиторов ИЛ-6 при осложненном течении COVID-19 продолжают уточнять. Большое число исследований посвящены тоцилизумабу. Так, в 2 китайских клинических исследованиях изучают тоцилизумаб как в сочетании с противовирусным препаратом фавипиравиром (ChiCTR2000030894), так и в виде монотерапии (ChiCTR2000029765). В крупное двойное слепое РПКИ III фазы COVACTA (NCT04320615), изучающее эффективность тоцилизумаба в дополнение к стандартной терапии при тяжелом COVID-19, планируют включить 330 пациентов, госпитализированных в США и других странах, конечные точки будут включать потребность в искусственной вентиляции легких и госпитализации в ОИТ. Еще в одном РПКИ (NCT04306705) у пациентов с COVID-19 будут сравнивать влияние на синдром высвобождения цитокинов лечения тоцилизумабом и экстракорпоральной детоксикации с использованием продленной заместительной почечной терапии. В США проводится двойное слепое РПКИ II/III фазы другого моноклонального антитела IgG1, специфичного к рецептору ИЛ-6, сарилумаба у пациентов, госпитализированных с тяжелой формой COVID-19 (NCT04315298). Запланировано сравнительное исследование сарилумаба и тоцилизумаба в/в или подкожно (NCT04322773). В нескольких исследованиях планируют изучать моноклональное антитело против ИЛ-6 силтуксимаб (NCT04322188, NCT04329650, NCT04330638), в одном из них силтуксимаб будут сравнивать с другими ГИБП, включая тоцилизумаб, рецепторный антагонист ИЛ-1 анакинру, сочетание тоцилизумаба и анакинры или силтуксимаба и анакинры (NCT04330638).

Перспективным направлением при COVID-19 является воздействие на Jak-STAT путь внутриклеточной сигнализации, играющей центральную роль в реализации сигнальной трансдукции, специфичной для цитокинов [65]. Иммуномодулирующие и противовоспалительные свойства ингибиторов ЈАК обусловлены многообразным влиянием на эффекты широкого спектра цитокинов, включая ИЛ-6. Таким образом, пероральные малые молекулы можно условно рассматривать как неселективные ингибиторы ИЛ-6 [75]. Ингибиторы JAK, применяемые в настоящее время при ревматоидном артрите, перспективны для лечения других иммуновоспалительных заболеваний, включая СВ [75, 76]. В эксперименте на химерной модели продемонстрировано влияние тофацитиниба на ключевые механизмы патогенеза васкулита крупных сосудов [77]. Таким образом, ингибиторы JАK потенциально способны подавлять воспаление, индуцированное коронавирусом, предотвращать повреждение легких и других органов.

Эффективность барицитиниба при COVID-19, помимо противовоспалительной активности, может быть обусловлена способностью регулировать раннюю стадию вирусной репликации за счет специфического ингибирования адаптерной киназы (adaptor-associated kinase, AAK) 1, играющей регуляторную роль в эндоцитозе, опосредованном клатрином, а также связывания еще с одним регулятором эндоцитоза, циклин $\mathrm{G}$-ассоциированной киназой [78, 79]. Полагают, что для ингибирования AAK1 достаточно дозы барицитиниба 2-4 мг в сутки, другие ингибиторы JАК в нетоксичных дозах не проявили способность ингибировать AAK1 [78, 79].

В настоящее время опубликованы результаты пилотного исследования барицитиниба у 12 больных COVID-19 с пневмонией средней тяжести (у 5 из 12 человек сопровождавшейся головной болью, у 2 - диареей), которые в течение 2 нед. получали препарат в дозе 4 мг в сутки. При этом клинико-лабораторное улучшение со снижением лихорадки, уровня СРБ и улучшением $\mathrm{SpO}_{2}$ было значительно более выражено в группе барицитиниба, по сравнению с контролем ( $p=0,000 ; 0,023 ; 0,000$ соответственно). Перевод в ОИТ потребовался 4 (33\%) из 12 пациентов контрольной группы и ни одному в группе лечения барицитинибом $(p=0,093)$. На 2-й неделе лечения были выписаны 7 (58\%) из 12 пациентов, получавших барицитиниб, и только один из 12 (8\%) в контрольной группе $(p=0,027)$ [80]. Лечение хорошо переносилось, не отмечено присоединения других инфекций, развития сердечно-сосудистых или гематологических нежелательных лекарственных реакций. Вместе с тем вопросы эффективности и безопасности ингибиторов JАК при COVID-19, в том числе тяжелого и катастрофического течения, требуют всестороннего анализа. Запланированы клинические испытания барицитиниба у госпитализированных пациентов с COVID-19 (NCT04340232, NCT04321993).

Обсуждая безопасность применения ГИБП и ингибиторов JAK при COVID-19, следует рассматривать течение COVID-19 у пациентов с ревматическими заболеваниями, но сведения об этом в настоящее время немногочисленны. Предварительные данные показывают, что пациенты с хроническим артритом, несмотря на лечение ГИБП или ингибиторами JAK, повидимому не имеют повышенного риска осложненного течения COVID-19, по сравнению с общей популяци- 
ей. Так, по данным S. Monti и соавт., среди 700 пациентов с тяжелым COVID-19 ни один не получал ранее лечение ГИБП или ингибиторами JAK, а среди заболевших COVID-19 4 пациентов с хроническим артритом (3 - ревматоидный артрит, 1 - спондилоартрит), ранее получавших лечение этанерцептом (2 пациента), абатацептом (1 пациент) или тофацинибом (1 пациент) и низкими дозами ГК (2 пациента), случаи тяжелого COVID-19 отсутствовали [81]. Вместе с тем данные вопросы требуют дальнейшего углубленного изучения.

Таким образом, COVID-19 тяжелого течения может сопровождаться распространенной патологией сосудов, прежде всего микроциркуляторного русла, опосредованной активацией преимущественно альтернативного и лектинового путей системы комплемента и тромбофилией, что следует учитывать при планировании новых стратегий лечения.

Конфликт интересов. Авторы заявляют об отсутствии конфликта интересов.

Финансирование. Исследование не имело спонсорской поддержки.

\section{Л И Т Е РАТ У PA / R E F ER E N C E S}

1. Nasonov E.L. Coronavirus disease 2019 (COVID-19): reflections of a rheumatologist. Scientific and practical rheumatology. 2020;58(2):123-32. (in Russian). doi: 10.14412/1995-44842020-123-132. [Насонов ЕЛ. Коронавирусная болезнь 2019 (COVID-19): размышления ревматолога. Научно-практическая ревматология. 2020;58(2):123-32. doi: 10.14412/1995-4484-2020123-132.]

2. Boraschi P. COVID-19 Pulmonary Involvement: Is Really an Interstitial Pneumonia? Acad. Radiol. 2020 Apr. 15. pii: S10766332(20)30202-6. doi:10.1016/j.acra.2020.04.010

3. Zhang W., Zhao Y., Zhang F., Wang Q., Li T., Liu Z. et al. The use of anti-inflammatory drugs in the treatment of people with severe coronavirus disease 2019 (COVID-19): The Perspectives of clinical immunologists from China. Clin. Immunol. 2020;214:108393. doi:10.1016/j.clim.2020.108393.

4. Zhang Y., Xiao M., Zhang S., Xia P., Cao W., Jiang W. et al. Coagulopathy and antiphospholipid antibodies in patients with Covid-19. N. Engl. J. Med. 2020;382(17):e38. doi:10.1056/NEJMc2007575.

5. Huang C., Wang Y., Li X., Ren L., Zhao J., Hu Y. et al. Clinical features of patients infected with 2019 novel coronavirus in Wuhan, China. Lancet. 2020;395(10223):497-506. doi: 10.1016/S01406736(20)30183-5.

6. Pan Y., Guan H., Zhou S., Wang Y., Li Q., Zhu T. et al. Initial CT findings and temporal changes in patients with the novel coronavirus pneumonia (2019-nCoV): a study of 63 patients in Wuhan, China. Eur. Radiol. 2020 Feb 13. doi: 10.1007/s00330-020-06731-x.

7. Shi H., Han X., Jiang N., Cao Y., Alwalid O., Gu J., Fan Y., Zheng C. Radiological findings from 81 patients with COVID-19 pneumonia in Wuhan, China: a descriptive study. Lancet Infect. Dis. 2020;20(4):425-434. doi:10.1016/S1473-3099(20)30086-4.

8. Qin C., Zhou L., Hu Z., Zhang S., Yang S., Tao Y. et al. Dysregulation of immune response in patients with COVID-19 in Wuhan, China. Clin. Infect. Dis. 2020 Mar 12. pii: ciaa248. doi: 10.1093/cid/ ciaa248.

9. Zhang J.J., Dong X., Cao Y.Y., Yuan Y.D., Yang Y.B., Yan Y.Q. et al. Clinical characteristics of 140 patients infected with SARS-CoV-2 in Wuhan, China. Allergy. 2020 Feb 19. doi: 10.1111/all.14238.

10. Wu D., Yang X.O. Th17 responses in cytokine storm of COVID-19: an emerging target of JAK2 inhibitor fedratinib. J. Microb. Immun. Infect. 2020. doi: 1016/j.jmii.2020.03.005.

11. Xu Z., Shi L., Wang Y., Zhang J., Huang L., Zhang C. et al. Pathological findings of COVID-19 associated with acute respiratory distress syndrome. Lancet Respir. Med. 2020;8(4):420-422. doi: 10.1016/S2213-2600(20)30076-X.

12. Zhou Y., Fu B., Zheng X. et al. Abberant pathogenic GM-CSF+T cells and inflammatory CD14+CD16+ monocyte in severe pulmo- nary syndrome patients of a new coronavirus. bioRxiv. 2020. doi: 10.1101/2020.02.12.945576.

13. Magro C., Mulvey J.J., Berlin D. et al. Complement associated microvascular injury and thrombosis in the pathogenesis of severe COVID-19 infection: A report of five cases. Transl. Res. 2020;(20):1931-5244. doi:10.1016/j.trsl.2020.04.007.

14. Gao Y., Li T., Han M., Li X., Wu D., Xu Y. et al. Diagnostic utility of clinical laboratory data determinations for patients with the severe COVID-19. J. Med. Virol. 2020 Mar 17. doi: 10.1002/jmv.25770.

15. Wan S., Yi Q., Fan S., Lv J., Zhang X., Guo L. Characteristics of lymphocyte subsets and cytokines in peripheral blood of 123 hospitalized patients with 2019 novel coronavirus pneumonia (NCP). Medrxiv. 2020. doi: 10.1101/2020.02.10.20021832.

16. Chen X., Zhao B., Qu Y., Chen Y., Xiong J., Feng Y. et al. Detectable serum SARS-CoV-2 viral load (RNAaemia) is closely correlated with drastically elevated interleukin 6 (IL-6) level in critically ill COVID-19 patients. Clin. Infect. Dis. 2020 Apr 17. pii: ciaa449. doi:10.1093/cid/ciaa449.

17. Liu T., Zhang J., Yang Y. et al. The potential role of interleukin 6 in monitoring severe case of coronavirus disesase. MedRxiv. 2020. doi: $10.1101 / 2020 / 03 / 01 / 20029769$.

18. Gao Y., Li T., Han M. et al. Diagnostic utility of clinical laboratory data determinations for patients with the severe COVID-19. J. Med. Virol. 2020 Mar 17. doi: 10.1002/jmv.25770.

19. Tang N., Li D., Wang X., Sun Z. Abnormal coagulation parameters are associated with poor prognosis in patients with novel coronavirus pneumonia. J. Thromb. Haemost. 2020 Feb 19. doi: 10.1111/jth. 14768.

20. Han H., Yang L., Liu R., Liu F., Wu K.L., Li J. et al. Prominent changes in blood coagulation of patients with SARS-CoV-2 infection. Clin. Chem. Lab. Med. 2020 Mar 16. pii: /j/cclm.aheadof-print/cclm-2020-0188/cclm-2020-0188.xml. doi:10.1515/ cclm-2020-0188.

21. Casey K., Iteen A., Nicolini R. Auten J. COVID-19 pneumonia with hemoptysis: Acute segmental pulmonary emboli associated with novel coronavirus infection. Am. J. Emerg. Med. 2020 Apr 8. pii: S0735-6757(20)30239-4. doi:10.1016/j.ajem.2020.04.011

22. Caruso D., Zerunian M., Polici M., Pucciarelli F., Polidori T., Rucci C. et al. Features of COVID-19 in Rome, Italy. Radiology. 2020;201237. doi: 10.1148/radiol.2020201237.

23. Leonard-Lorant I., Delabranche X., Severac F., Helms J., Pauzet C., Collange O. et al. Acute pulmonary embolism in COVID-19 patients on ct angiography and relationship to D-dimer levels. Radiology. 2020;201561. doi: 10.1148/radiol.2020201561.

24. Grillet F., Behr J., Calame P., Aubry S., Delabrousse E. Acute pulmonary embolism associated with COVID-19 pneumonia detected by pulmonary CT angiography. Radiology. 2020;201544. doi: 10.1148/ radiol.2020201544.

25. Klok F.A., Kruip M.J.H.A., van der Meer N.J.M., Arbous M.S., Gommers D.A.M.P.J., Kant K.M. et al. Incidence of thrombotic complications in critically ill ICU patients with COVID-19. Thromb. Res. 2020 Apr 10. pii: S0049-3848(20)30120-1. doi:10.1016/j.thromres.2020.04.013.

26. Bellosta R., Luzzani L., Natalini G., Pegorer M.A., Attisani L., Cossu L.G. et al. Acute limb ischemia in patients with COVID-19 pneumonia. J. Vasc. Surg. 2020 Apr 29. doi: 10.1016/j.jvs.2020.04.483. Epub ahead of print. PMCID: PMC7188654.

27. Leisman D.E., Deutschman C.S., Legrand M. Facing COVID-19 in the ICU: vascular dysfunction, thrombosis, and dysregulated inflammation. Intensive Care Med. 2020 Apr 28. doi: 10.1007/s00134-02006059-6.

28. Zheng Y.Y., Ma Y.T., Zhang J.Y., Xie X. COVID-19 and the cardiovascular system. Nat. Rev. Cardiol. 2020 May;17(5):259-260. doi: 10.1038/s41569-020-0360-5.

29. Gianotti R., Veraldi S., Recalcati S., Cusini M., Ghislanzoni M., Boggio F., Fox L.P. Cutaneous Clinico-Pathological Findings in three COVID-19-Positive Patients Observed in the Metropolitan Area of Milan, Italy. Acta Derm. Venereol. 2020 Apr 21. doi: 10.2340/00015555-3490.

30. Guan W.J., Ni Z.Y., Hu Y., Liang W.H., Ou C.Q., He J.X. et al.; China Medical Treatment Expert Group for Covid-19. Clinical Characteristics of Coronavirus Disease 2019 in China. N. Engl. J. Med. 2020 Feb 28. doi: 10.1056/NEJMoa2002032.

31. Recalcati S. Cutaneous manifestations in COVID-19: a first perspective. J. Eur. Acad. Dermatol. Venereol. 2020 Mar 26. doi: 10.1111/ jdv.16387.

32. Galván Casas C., Català A., Carretero Hernández G., Rodríguez-Jiménez P., Fernández Nieto D., Rodríguez-Villa Lario A. et al. 
Classification of the cutaneous manifestations of COVID-19: a rapid prospective nationwide consensus study in Spain with 375 cases. $B r$. J. Dermatol. 2020 Apr 29. doi: 10.1111/bjd.19163.

33. Mao L., Jin H., Wang M., Hu Y., Chen S., He Q. et al. Neurologic Manifestations of Hospitalized Patients With Coronavirus Disease 2019 in Wuhan, China. JAMA Neurol. 2020 Apr 10. doi: 10.1001/ jamaneurol.2020.1127.

34. Giacomelli A., Pezzati L., Conti F., Bernacchia D., Siano M., Oreni L. et al. Self-reported olfactory and taste disorders in SARSCoV-2 patients: a cross-sectional study. Clin. Infect. Dis. 2020 Mar 26. pii: ciaa330. doi: 10.1093/cid/ciaa330.

35. Su H., Yang M., Wan C., Yi L.X., Tang F., Zhu H.Y. et al. Renal histopathological analysis of 26 postmortem findings of patients with COVID-19 in China. Kidney Int. 2020 Apr 9. pii: S00852538(20)30369-0. doi:10.1016/j.kint.2020.04.003.

36. Naumenko ZK, Chernyak AV, Nekludova GV, Chuchalin AG. Ventilation-perfusion ratio. Practical pulmonology. 2018;4:86-90. (in Russian). [Науменко ЖК, Черняк АВ, Неклюдова ГВ, Чучалин АГ. Вентиляционно-перфузионное отношение. Практическая пульмонология. 2018;4:86-90.]

37. Yao X.H., Li T.Y., He Z.C., Ping Y.F., Liu H.W., Yu S.C. et al. A pathological report of three COVID-19 cases by minimally invasive autopsies. Zhonghua Bing Li Xue Za Zhi. 2020;49(0):E009. doi: 10.3760/cma.j.cn112151-20200312-00193.

38. Mastellos D.C., Ricklin D., Lambris J.D. Clinical promise of next-generation complement therapeutics. Nat. Rev. Drug. Discov. 2019;18(9):707-29. doi:10.1038/s41573-019-0031-6.

39. Tinti M.G., Carnevale V., Inglese M., Molinaro F., Bernal M., Migliore A., De Cata A. Eculizumab in refractory catastrophic antiphospholipid syndrome: a case report and systematic review of the literature. Clin. Exp. Med. 2019;19(3):281-288. doi: 10.1007/s10238019-00565-8.

40. Legendre C.M., Licht C., Muus P., Greenbaum L.A., Babu S., Bedrosian C. et al. Terminal complement inhibitor eculizumab in atypical hemolytic-uremic syndrome. N. Engl. J. Med. 2013;368(23):21692181. doi: 10.1056/NEJMoa1208981.

41. Licht C., Greenbaum L.A., Muus P., Babu S., Bedrosian C.L., Cohen D.J. et al. Efficacy and safety of eculizumab in atypical hemolytic uremic syndrome from 2-year extensions of phase 2 studies. Kidney Int. 2015;87(5):1061-1073. doi: 10.1038/ki.2014.423.

42. Greenbaum L.A., Fila M., Ardissino G., Al-Akash S.I., Evans J., Henning P. et al. Eculizumab is a safe and effective treatment in pediatric patients with atypical hemolytic uremic syndrome. Kidney Int. 2016;89(3):701-11. doi: 10.1016/j.kint.2015.11.026.

43. Fakhouri F., Hourmant M., Campistol J.M., Cataland S.R., Espinosa M., Gaber A.O. et al. Terminal Complement Inhibitor Eculizum$\mathrm{ab}$ in Adult Patients With Atypical Hemolytic Uremic Syndrome: A Single-Arm, Open-Label Trial. Am J. Kidney Dis. 2016;68(1):84-93. doi: 10.1053/j.ajkd.2015.12.034.

44. McKeage K. Ravulizumab: First Global Approval. Drugs. 2019;79(3):347-352. doi: 10.1007/s40265-019-01068-2.

45. McNamara L.A., Topaz N., Wang X., Hariri S., Fox L., MacNeil J.R. High Risk for Invasive Meningococcal Disease Among Patients Receiving Eculizumab (Soliris) Despite Receipt of Meningococcal Vaccine. MMWR Morb. Mortal Wkly Rep. 2017;66(27):734-7. doi:10.15585/mmwr.mm6627e1.

46. Ito S., Hidaka Y., Inoue N., Kaname S., Kato H., Matsumoto M. et al. Safety and effectiveness of eculizumab for pediatric patients with atypical hemolytic-uremic syndrome in Japan: interim analysis of post-marketing surveillance. Clin. Exp. Nephrol. 2019;23(1):112121. doi: 10.1007/s10157-018-1610-2.

47. Jayne D.R.W., Bruchfeld A.N., Harper L., Schaier M., Venning M.C., Hamilton P. et al.; CLEAR Study Group. Randomized Trial of C5a Receptor Inhibitor Avacopan in ANCA-Associated Vasculitis. J. Am Soc. Nephrol. 2017;28(9):2756-67. doi:10.1681/ ASN.2016111179.

48. Merkel P.A., Niles J., Jimenez R. et al. A randomized clinical trial of CCX168, an orally administered C5aR inhibitor for treatment of patients with ANCA-associated vasculitis. Amer. Coll. Rheumatol. 2016;978.

49. Merkel P.A., Jayne D.R., Wang C., Hillson J., Bekker P. Evaluation of the safety and efficacy of avacopan, a c5a receptor inhibitor, in patients with antineutrophil cytoplasmic antibody-associated vasculitis treated concomitantly with rituximab or cyclophosphamide/azathioprine: protocol for a randomized, double-blind, active-controlled, phase 3 trial. JMIR Res. Protoc. 2020;9(4):e16664. doi:10.2196/16664.
50. Diurno F., Numis F.G., Porta G., Cirillo F., Maddaluno S., Ragozzino A. et al. Eculizumab treatment in patients with COVID-19: preliminary results from real life ASL Napoli 2 Nord experience. Eur. Rev. Med. Pharmacol. Sci. 2020;24(7):4040-4047. doi:10.26355/ eurrev_202004_20875.

51. Shagdarsuren E., Wellner M., Braesen J.H. Complement activation in angiotensin II-induced organ damage. Circ. Res. 2005;97:716-724.

52. Phan T. Novel coronavirus: From discovery to clinical diagnostics. Infect. Genet. Evol. 2020 Apr;79. doi: 10.1016/j.meegid.2020.104211.

53. Zhao Y., Zhao Z., Wang Y., Zhou Y., Ma Y., Zuo W. Single-cell RNA expression profiling of ACE2, the putative receptor of Wuhan 2019-nCov. Biorxiv. 2020;2020(1):26.919985. doi: 10.1101/2020.01.26.919985.

54. Rodrigues Prestes T.R., Rocha N.P., Miranda A.S., Teixeira A.L., Simoes-E-Silva A.C. The Anti-Inflammatory Potential of ACE2/Angiotensin-(1-7)/Mas Receptor Axis: Evidence from Basic and Clinical Research. Curr. Drug. Targets. 2017;18(11):1301-1313. doi: 10. 2174/1389450117666160727142401

55. Van de Veerdonk F., Netea M.G., van Deuren M., van der Meer J.W., de Mast Q, Bruggemann RJ, van der Hoeven H. Kinins and Cytokines in COVID-19: A Comprehensive Pathophysiological Approach. Preprints. 2020;2020040023. doi: 10.20944/preprints202004.0023.v1.

56. Srivastava P., Badhwar S., Chandran D.S., Jaryal A.K., Jyotsna V.P., Deepak K.K. Imbalance between Angiotensin II - Angiotensin (1-7) system is associated with vascular endothelial dysfunction and inflammation in type 2 diabetes with newly diagnosed hypertension. Diabetes Metab. Syndr. 2019;13(3):2061-8. doi: 10.1016/j. dsx.2019.04.042.

57. Hanff T.C., Harhay M.O., Brown T.S., Cohen J.B., Mohareb A.M. Is There an Association Between COVID-19 Mortality and the Renin-Angiotensin System - a Call for Epidemiologic Investigations. Clinical Infectious Diseases. 2020. PMID 32215613 doi:10.1093/ $\mathrm{cid} / \mathrm{ciaa} 329$.

58. Cheng H., Wang Y., Wang G.Q. Organ-protective effect of angiotensin-converting enzyme 2 and its effect on the prognosis of COVID-19. J. Med. Virol. 2020 Mar 27. doi: 10.1002/jmv.25785.

59. Zhou Y., Hou Y., Shen J., Huang Y., Martin W., Cheng F. Network-based drug repurposing for novel coronavirus 2019-nCoV/ SARS-CoV-2. Cell. Discov. 2020;6:14. doi: 10.1038/s41421-0200153-3.

60. Liu C., Ma Y., Su Z. et al. Meta-Analysis of Preclinical Studies of Fibrinolytic Therapy for Acute Lung Injury. Front Immunol. 2018;9:1898. doi:10.3389/fimmu.2018.01898.

61. Moore H.B., Barrett C.D., Moore E.E., McIntyre R.C., Moore P.K. Talmor D.S., Moore F.A., Yaffe M.B. Is there a role for tissue plasminogen activator (tPA) as a novel treatment for refractory COVID-19 associated acute respiratory distress syndrome (ARDS)? J. Trauma Acute Care Surg. 2020 Mar 20. doi: 10.1097/ TA.0000000000002694.

62. Choudhury R., Barrett C.D., Moore H.B., Moore E.E., McIntyre R.C., Moore P.K. et al. Salvage use of tissue plasminogen activator (tPA) in the setting of acute respiratory distress syndrome (ARDS) due to COVID-19 in the USA: a Markov decision analysis. World J. Emerg. Surg. 2020;15(1):29. doi:10.1186/s13017-020-00305-4.

63. Wang J., Hajizadeh N., Moore E.E., McIntyre R.C., Moore P.K., Veress L.A. et al. Tissue plasminogen activator (tPA) treatment for COVID-19 associated acute respiratory distress syndrome (ARDS): A Case Series. J. Thromb. Haemost. 2020 Apr 8. doi: 10.1111/ jth.14828.

64. Wong C.K., Lam C.W., Wu A.K., Ip W.K., Lee N.L., Chan I.H. et al. Plasma inflammatory cytokines and chemokines in severe acute respiratory syndrome. Clin. Exp. Immunol. 2004;136(1):95-103.

65. Mehta P., McAuley D.F., Brown M., Sanchez E., Tattersall R.S., Manson J.J. COVID-19: consider cytokine storm syndromes and immunosuppression. Lancet. 2020. doi: 10.1016/S0140-6736(20)30628-0.

66. Nasonov E.L., Lila A.M. Interleukin 6 inhibition in immuno-inflammatory rheumatic diseases: achievements, prospects and hopes. Scientific and practical rheumatology. 2017;55(6):590599. https://doi.org/10.14412/1995-4484-2017-590-599. (in Russian). [Насонов Е.Л., Лила А.М. Ингибиция интерлейкина 6 при иммуновоспалительных ревматических заболеваниях: достижения, перспективы и надежды. Научно-практическая ревматология. 2017;55(6):590-9. https://doi.org/10.14412/19954484-2017-590-599.]

67. Shimabukuro-Vornhagen A., Gödel P., Subklewe M., Stemmler H.J., Schlößer H.A., Schlaak M. Et al. Cytokine release syndrome. J. Immunother. Cancer. 2018;6(1):56. doi:10.1186/s40425-018-0343-916. 
Обзоры и лекции

68. Behrens E.M., Koretzky G.A. Review: Cytokine Storm Syndrome: Looking Toward the Precision Medicine Era. Arthritis Rheum. 2017;69(6):1135-1143. doi: 10.1002/art.40071.

69. Yildiz H., Neste E.V.D., Defour J.P., Danse E., Yombi J.C. Adult haemophagocytic lymphohistiocytosis: a review. Qjm. Mon. J. Assoc. Physicians. 2020. doi: 10.1093/qjmed/hcaa011.

70. Conti P., Ronconi G., Caraffa A., Gallenga C.E., Ross R., Frydas I., Kritas S.K. Induction of pro-inflammatory cytokines (IL-1 and IL6) and lung inflammation by Coronavirus-19 (COVI-19 or SARSCoV-2): anti-inflammatory strategies. J. Biol. Regul. Homeost. Agents. 2020;34(2). pii: 1. doi: 10.23812/CONTI-E.

71. Harigai M., Tsutsumino M., Takada H., Nagasaka K. Molecular targeted therapies for microscopic polyangiitis and granulomatosis with polyangiitis. Korean J. Intern. Med. 2019;34(3):492-503. doi: $10.3904 / \mathrm{kjim} .2018 .366$.

72. Tisoncik J.R., Korth M.J., Simmons C.P., Farrar J., Martin T.R., Katze M.G. Into the eye of the cytokine storm. Microbiol. Mol. Biology Rev. Mmbr. 2012;76:16-32. doi: 10.1128/mmbr.05015-11.

73. Misra D.P., Ahmed S., Agarwal V. Is biological therapy in systemic sclerosis the answer? Rheumatol. Int. 2020;40(5):679-694. doi: 10.1007/s00296-020-04515-6.

74. Xu X., Han M., Li T., Sun W., Wang D., Fu B. et al. Effective treatment of severe COVID-19 patients with tocilizumab. China Xiv.

75. Nasonov E.L, Lila A.M. Janus kinase inhibitors in immuno-inflammatory rheumatic diseases: new opportunities and prospects. Scientific and practical rheumatology. 2019;57(1):8-16. https://doi. org/10.14412/1995-4484-2019-8-16. (in Russian). [Насонов Е.Л.,
Лила А.М. Ингибиторы Янус-киназ при иммуновоспалительных ревматических заболеваниях: новые возможности и перспективы. Научно-практическая ревматология. 2019;57(1):816. https://doi.org/10.14412/1995-4484-2019-8-16.]

76. You H., Xu D., Zhao J., Li J., Wang Q., Tian X. et al. JAK inhibitors: prospects in connective tissue diseases. Clin. Rev. Allergy Immunol. 2020 Mar 28. doi: 10.1007/s12016-020-08786-6.

77. Zhang H., Watanabe R., Berry G.J., Tian L., Goronzy J.J., Weyand C.M. Inhibition of JAK-STAT Signaling Suppresses Pathogenic Immune Responses in Medium and Large Vessel Vasculitis. Circulation. 2018 May;137(18):1934-48. doi:10.1161/CIRCULATIONAHA. 117.030423 .

78. Richardson P., Griffin I., Tucker C. et al. Baricitinib as potential treatment for $2019-\mathrm{nCoV}$ acute respiratory disease. Lancet. 2020;395(10223):e30-31. doi: 10.1016/S0140-6736(20)30304-4.

79. Stebbing J., Phelan A., Griffin I. et al. COVID-19: combining antiviral and anti-inflammatory treatments. Lancet Infect. Dis. $2020 \mathrm{Feb}$ 27. doi: 10.1016/S1473-3099(20)30132-8.

80. Cantini F., Niccoli L., Matarrese D., Nicastri E., Stobbione P., Goletti D. Baricitinib therapy in COVID-19: A pilot study on safety and clinical impact. J. Infect. 2020 Apr 22. pii: S0163-4453(20)30228-0. doi: 10.1016/j.jinf.2020.04.017

81. Monti S., Balduzzi S., Delvino P., Bellis E., Quadrelli V.S., Montecucco C. Clinical course of COVID-19 in a series of patients with chronic arthritis treated with immunosuppressive targeted therapies. Ann. Rheum. Dis. 2020 May;79(5):667-668. doi:10.1136/ annrheumdis-2020-217424. 